\title{
OPTIMISATION OF THE BALUBA EAST ORE TREATMENT
}

\author{
C. Chabuka ${ }^{1}$ and L. K. Witika ${ }^{2}$ \\ ${ }^{I}$ ZCCM, Nkana Division, Kitwe, Zambia, \\ ${ }^{2}$ University of Zambia, Box 32379, Lusaka, Zambia \\ Lwitika@mines.unza.zm
}

\begin{abstract}
The Baluba east concentrator is part of the Roan Antelope Mining Corporation (RAMCO) which is a unit of the Binani Group of Companies. It treats an ore which is a mixture of sulphide and oxide copper minerals. In the flotation of mixed sulphide - oxide ores, the sulphide minerals are floated first, then followed by a sulphidisation step of the oxide minerals to effect their flotation.
\end{abstract}

This test work was carried out because of a decrease in the grades and recoveries obtainable during the period of January 1998 up to around September 1998. This was so despite having an above average head grade of $1.91 \%$ Tcu.

The optimum mesh of grind was found to be $65 \%$ passing $75 \mu \mathrm{m}$ using release analysis and the conclusions were drawn on the basis of flotation kinetics.

The optimisation of reagents addition was done using a FACTORIAL DESIGN of experiments to improve the reliability of the result and Analysis of Variance(ANOVA) and the F-test were used to draw meaningful conclusions.

Dosages of $120 \mathrm{~g} / \mathrm{t}$ collector (SIPX) and $100 \mathrm{~g} / \mathrm{t}$ conditioner (NaHS) were obtained as the optimum reagent levels. The associated concentrate grade was $26.10 \% \mathrm{TCu}$ (without a cleaning stage) at a recovery of $90.16 \% \mathrm{TCu}$.

This adjustment in reagent consumption rates, if effected, would introduce a $10 \%$ reduction in collector consumption and a 50\% reduction in conditioner consumption, which clearly indicates a significant reduction in the overall costs of reagents per tonne ore treated.

Keywords: Sulphides, oxides, reagents, concentrates.

\section{INTRODUCTION}

Froth flotation, as practised today had its industrial beginnings over 80 years ago in Australia. The first froth flotation plant in the United States began in 1911 at the Timber Butte in Basin, Montana, to treat slimes for sphalerite recovery [1].

The importance of the froth flotation process to the economy of the whole industrial world is considered to be enormous. Without the development of flotation many familiar metals and inorganic raw materials would be exceedingly scarce and costly, because the high grade ores, which could be processed by simple physical and mechanical methods have long since been depleted [2].
Flotation has permitted the mining of low grade and complex ores which would have been worthless if it had been necessary to rely on the time honoured method of gravity concentration.

During the past decade or two, the mineral industry has had to operate under a variety of constraints among which includes:

(a) higher energy costs due mainly to costs of fuel

(b) a general decrease in ore grades often combined with increased complexity of mineralogy

(c) ever increasing environmental constraints which usually increase costs 
These and other economic pressures have pressed the mineral industry to seek more efficient and highly productive means of processing minerals.

As is well known to all mineral processing Scientists and Engineers, flotation involves the capture of small mineral particles by bubbles in a slurry, followed by their levitation to the surface of the slurry, where they are collected in a froth.

Finely crushed ore is agitated in water with the addition of air or other gases. Various chemicals are added to cause the selected mineral particles hydrophobic and eventually attach themselves to the air or gas bubble which carry these mineral particles in a froth [3].

It is a well known fact that sulphide ore minerals are among the most suitable minerals for enrichment through flotation, due to their excellent flotation properties. The inability of sulphide minerals to form hydrogen bonds is considered to be the principal reason why they, unlike the oxygen containing minerals are not strongly hydrophilic. The fact that most of them are either conductors or semi-conductors, they tend to under go electrochemical reactions with Thiol collectors leading to their hydrophobicity [4].

Unlike sulphide minerals, which are naturally hydrophobic, oxide minerals are inherently hydrophilic and as a practice, the surfaces of oxides require modification with sodium sulphide or sodium hydrosulphide through the surface adsorption of sulphide ions on them. The sulphide ions form a pseudo-sulphide mineral surface and with the adorption of a suitable collector on such a mineral surface, flotation may occur [5].

One laboratory method based on flotation kinetics that can be used to establish the Optimum mesh of grind is release analysis. It is based on the understanding that when an ore is at its optimum size, it gives the best response to flotation as most of the mineral grains are fully liberated. Attainment of this condition is indicated principally by the flotation rate attaining a maximum. Two stages of this laboratory test work can be distinguished [6].

(a) Separation of floatables from non-floatables is the stage where floatable material is separated from nonfloatables until the froth has become barren. The floatables are floated as many times as is necessary, adding boaster collector at various stages if necessary. This is followed by a cleaning stage to remove entrained gangue [7].

(b) Fractionation of floatables which involves partitioning of the floatable into fractions according to their kinetics [7].
This work was carried out to address the increasing low grades and recoveries for the sometime at Baluba Concentrator at RAMCO suspected to be due to the non optimal liberation of minerals and the addition of different reagents.

\section{EXPERIMENTALMETHOD}

About 200kg of feed to the Baluba flotation circuit was collected by using the sampling all the stream part of the time method [8]. This was achieved by passing a rectangular scoop with a log handle across the belt feed to the ball mill for a period of 10 hours. The ore was dried overnight in the oven and then crushed to $100 \%$ passing $-2 \mathrm{~mm}$ sieve aperture in a laboratory cone crusher. After thoroughly, mixing the sample was split by conning and quartering and subsequently in a riffle splitter to ensure good blending. Samples were then packed in plastic containers in order to prevent oxidation. A small random sub-sample was taken to the laboratory for chemical analysis and another was sent for mineralogical analysis.

The following equipment and materials were used in this testwork:

(a) a laboratory cone crusher with a set of minus $2 \mathrm{~mm}$

(b) a laboratory tumbling mill with grinding media of 12 rods and dimensions $20 \mathrm{~mm}$ diameter, $290 \mathrm{~mm}$ length.

(c) a set of laboratory sieve complete with a rotap sieve shaker

(d) a 2.5 litre Wemco lab. Fay flotation machine with adjustable rotor speed

(e) an electronic balance

(f) a riffle splitter, a cubic rotary mixer and a stop watch.

The reagents used on this circuit are shown in the table below:

Table 1: Table of reagents used on the Baluba East Circuit

\begin{tabular}{|l|l|l|}
\hline TRADE NAME & CHEMICAL NAME & USAGE \\
\hline SIPX & $\begin{array}{l}\text { SODIUM } \\
\text { ISOPROPYL } \\
\text { XANTHATE }\end{array}$ & COLLECTOR \\
\hline NaHS & $\begin{array}{l}\text { SODIUM } \\
\text { HYDROSULPHIDE }\end{array}$ & MODIFIER \\
\hline D-14 & $\begin{array}{l}\text { ALKYL POLY } \\
\text { PROPYLENE ETHER }\end{array}$ & FROTHER \\
\hline D-250E & $\begin{array}{l}\text { POLY PROPYLINE } \\
\text { GLYCO ETHER }\end{array}$ & FROTHER \\
\hline
\end{tabular}


To determine the grinding time, seven, $1 \mathrm{~kg}$ samples were ground at 4, 7, 8, 9, 10, 11 and 12 minutes, in duplicate using a laboratory rod mill to determine which time gives a grind of $65 \%$ solids passing $75 \mu \mathrm{m}$ sieve aperture which is the standard for the Baluba East Flotation Circuit. Dry and wet sieve analysis was then carried out after grinding to determine the percent solids passing $75 \mu \mathrm{m}$.

Release analysis was done in the following procedure:

The rod mill was charged with $600 \mathrm{ml}$ of water (standard volume for the mill), $1 \mathrm{~kg}$ of the ore, the grinding media and the collector, sodium isopropyl xanthate (SIPX) at the plant optimised dosage of $130 \mathrm{~g} / \mathrm{t}$ and then ground for 4 minutes.

After grinding the pulp was transferred into a flotation cell and the level made up to 2.5 litres. Three drops of the frother, D14 was added (an excess of frother should be avoided as this causes entrainment of gangue) and two minutes conditioning time allowed before turning the air tap open. The mineralised sulphide froth was then carefully skimmed until the froth became completely barren. Oxide bearing minerals were then recovered by the addition of modifier, sodium hydrosulphide (NaHS) at a dosage of $200 \mathrm{~g} / \mathrm{t}$ and a conditioning period of one minute allowed. The air tap was then opened and the mineralised froth was barren.

The froth was then refloated as many times as necessary and more boaster collector added if necessary to obtain a tailing with a negligible quantity of solids. This flotation procedure was repeated until another sulphide - oxide concentrate mixture was obtained. The two concentrates were then mixed and the resulting composite concentrate after a cleaning stage, partitioned in $0.5,1.5,3.5,6.5$ and greater than 6.5 floating fractions.

The concentrate fractions obtained were then dried in an oven and eventually sent for copper assay. The same procedure was employed for mill residence times of 7, 8, 9, 10, 11 and 12 minutes.

\section{DISCUSSION OF RESULTS}

The results of the chemical analysis for the sample done by Analytical Services are shown below:

$\begin{array}{llc}\% \mathrm{TCu} & \% \mathrm{ASCu} & \% \mathrm{TCo} \\ 2.16 & 0.164 & 0.64\end{array}$

The mineralogical analysis of the sample was done in order to: (a) identify the various valuable and gangue mineral species occur,

(b) establish the proportions in which these mineral species occur,

(c) obtain quantitative information on the liberation characteristics of the valuable minerals.

The table below shows the relative abundance of the constituent minerals of the Baluba East flotation circuit feed.

Table 2. Approximate relative abundance

\begin{tabular}{|l|l|l|l|}
\hline SULPHIDES & $\%$ & OXIDES & $\%$ \\
\hline CHALCOPYRITE & 34.00 & MALACHITE & 5.00 \\
\hline CHALOCITE & 26.80 & CUPRITE & 2.44 \\
\hline PYRITE & 24.40 & PSEUDOMALACHITE & $<0.1$ \\
& & & \\
\hline BORNITE & 7.32 & CHRYSOCOLLA & \\
\hline CARROLITE & $<0.1$ & - & \\
\hline NATIVE COPPER & $<0.1$ & - & \\
\hline
\end{tabular}

The mineralogical analysis shows that the ore is predominantly composed of sulphide i.e. Chalcopyrite $\left(\mathrm{CuFeS}_{2}\right)$, followed by Chalcocite $\left(\mathrm{Cu}_{2} \mathrm{~S}\right)$ and Pyrite $\left(\mathrm{FeS}_{2}\right)$. The oxides are represented by Malachite $\left(\mathrm{CuCO}_{3} \cdot \mathrm{Cu}(\mathrm{OH})_{2}\right)$ and Cuprite $\left(\mathrm{Cu}_{2} 0\right)$. The other oxides were less than $0.1 \%$ with Chrysocolla $\left(\mathrm{CuSiO}_{3} .2 \mathrm{H}_{2} \mathrm{O}\right)$ represented as trace.

Figure 1 below shows a plot of weight solids \% passing 75 $\mu \mathrm{m}$ against grinding time which revealed that the optimum grinding time was 9 minutes which gave $65 \%-67 \%$ solids passing $75 \mu \mathrm{m}$

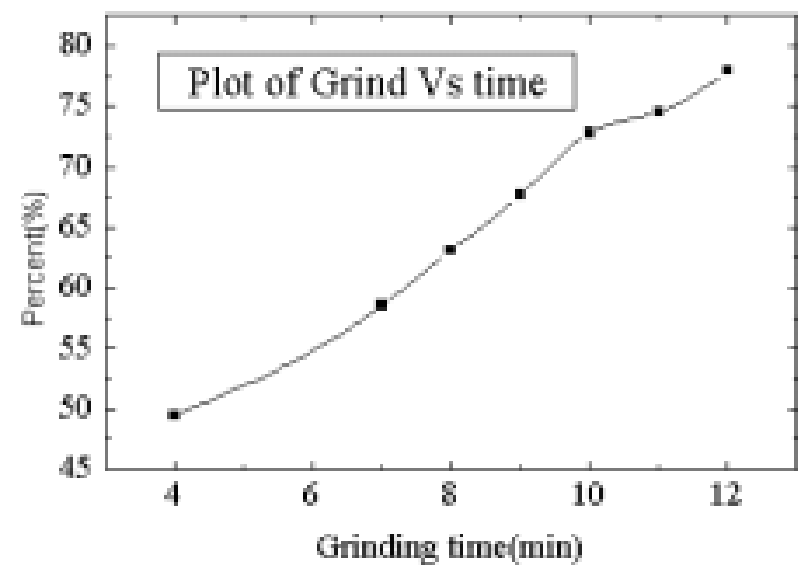

Figure 1: Weight percent passing $75 \mathrm{~m}$ verses grinding time 
Determination of the optimum mesh of grind or degree of liberation of the ore was done using release analysis and the results obtained are shown in the figure 2 below.

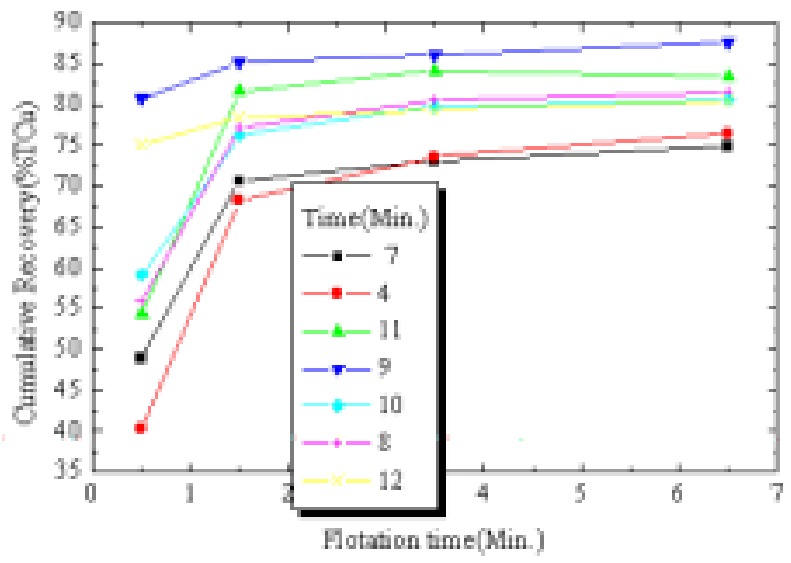

Figure 2: Shows the relationship between the cumulative recovery and flotation time

From the diagram above, it is apparent that the optimum mesh of grind the ore was $65 \%$ solids passing $75 \mathrm{~m}$ (i.e 9 minutes grinding since it gave both the highest grades and recoveries.

\section{Optimisation of Collector and Modifier}

Using the apparatus mentioned earlier and after grinding for 9 minutes i.e. to the optimum mesh of grind size $65 \%$ solids passing $75 \mathrm{um}$, another flotation testwork was done, this time to determine the optimum combination of reagents at which improved grades and acceptable recoveries are attained. The standard laboratory flowsheet used is shown in figure 3.

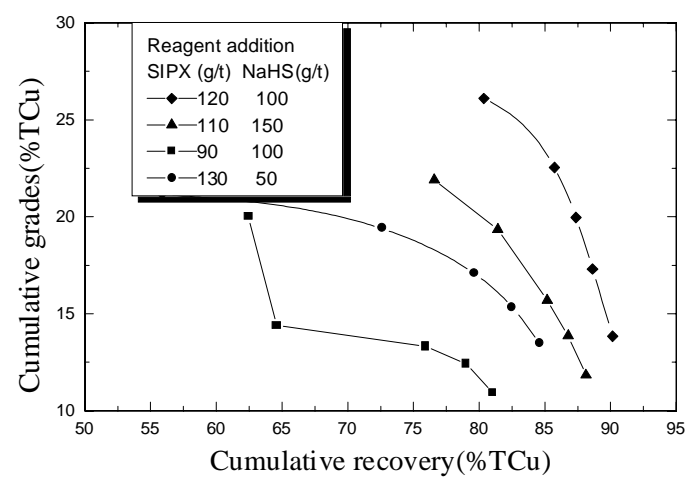

Figure 3: Shows the relationship between the grades and recoveries at different reagent dosage.
The collector and modifier dosage levels were the parameters of interest and the levels of combinations are shown in the table 2 below.

Table 2 shows the combinations of reagents at constant frother used for the optimisation of the collector and modifier in this test work.

\begin{tabular}{|l|l|l|l|l|}
\hline SIPX/NaHS & $200 \mathrm{~g} / \mathrm{t}$ & $150 \mathrm{~g} / \mathrm{t}$ & $100 \mathrm{~g} / \mathrm{t}$ & $50 \mathrm{~g} / \mathrm{t}$ \\
\hline $130 \mathrm{~g} / \mathrm{t}$ & 1 & 5 & 9 & 13 \\
\hline $120 \mathrm{~g} / \mathrm{t}$ & 2 & 6 & 10 & 14 \\
\hline $110 \mathrm{~g} / \mathrm{t}$ & 3 & 7 & 11 & 15 \\
\hline $90 \mathrm{~g} / \mathrm{t}$ & 4 & 8 & 12 & 16 \\
\hline
\end{tabular}

These floats were done in duplicate and therefore the total number of combinations was:

$(4 * 4 * 1) * 2=32$ floats

\section{pHOPTIMISATION}

Although the importance of $\mathrm{pH}$ in floatation systems has been extensively reviewed, the $\mathrm{pH}$ optimisation in this test work was deemed not to be critical to the plant operations at the time of the testwork.

\section{REAGENT OPIMISATIONUSING THEFACTORIAL DESIGNAPPROACH}

The most common practice in experiments involving the determination of optimum conditions for most metallurgical processes in which several factors have an influence on the final results of a process operation is the one-variableat a-time approach. In this method, only the process variable is manipulated at each time and the rest are "held constant".

It has however been argued extensively that such analysis of results are prone to drawing of wrong conclusions. This is because when one process variable is changed, many other variables will change at the same time so that the effect of the manipulated variable alone is overshadowed [9]. These investigation processes usually involving a larger number of parameters and are often laborious and tedious, leading to an extensive experimental program that yields results which are not easy interpreted. 
It would therefore, be very helpful if it were possible to determine in a swift manner which of the parameters are mainly in determining which of the parameters warrant further study and which of these are of relatively little importance.

The factorial design of experiments in conjuction with the Analysis of Variance (ANOVA) statistical method were used in the optimisation of reagent dosages and analysis of results. The factorial design of experiments is a technique of a priori experimental programme design; where parameters are changed simultaneously but in a coherent manner, and this offers the advantage of obtaining quantitative information not only about the effect of the main variables of the process, but also of their mutual interactions [2]

\section{THE ANALYSIS OF VARIANCE - ANOVA}

The ANOVA is a method for splitting the total variation of our data into meaningful components that measure difference sources of variation.

The analysis of variance was the basis for the conclusions which were drawn from the results. The F - test was employed and its underlying principle when adapted to this situation may be explained as follows:

During flotation, if a change in the output variable (say the recovery) associated with a particular treatment e.g. collection at different levels, are due to the effect of that treatment alone and not as a result of experimental error.

In this test work, the treatment was either an increase or a decrease in the dosages of the reagents used and the statistic F was therefore defined as:

$$
\begin{aligned}
& \mathrm{F}=\quad \text { Variance within the recoveries at level of interest } \\
& \text { Variance within the recoveries for the entire population }
\end{aligned}
$$

\section{Application of the ANOVA on the results}

Table 3 shows the combination of reagent dosages with their corresponding recoveries in duplicate.
Table 3: Recover of total copper at different dosages in duplicate

\begin{tabular}{|c|l|l|l|l|}
\hline $\mathrm{g} / \mathrm{t}$ & \multicolumn{4}{|c|}{ RECOVERIES - - - Tcu } \\
\hline Dose Rates & \multicolumn{4}{|c|}{ Conditioner - NaHS g/t } \\
\hline Collector-SIPX & 50 & 100 & 150 & 200 \\
\hline 90 & 89.47 & 88.91 & 65.58 & 90.22 \\
& 63.85 & 85.90 & 90.63 & 88.50 \\
\hline \multirow{2}{*}{110} & 89.38 & 64.76 & 88.13 & 89.61 \\
\cline { 2 - 5 } & 84.30 & 82.61 & 81.05 & 82.60 \\
\hline \multirow{2}{*}{120} & 88.41 & 90.16 & 68.75 & 89.47 \\
& 63.69 & 87.98 & 88.49 & 87.23 \\
\hline \multirow{2}{*}{130} & 70.08 & 68.63 & 88.53 & 86.38 \\
\cline { 2 - 5 } & 84.60 & 84.84 & 54.53 & 88.54 \\
\hline
\end{tabular}

\section{Calculations on the ANOVA}

We start by looking at recovery of total copper. Table 3 can be rewritten in terms of the sums of the recoveries in

\begin{tabular}{|c|c|c|c|c|c|c|}
\hline Collector & \multicolumn{4}{|c|}{$\% \mathrm{Tcu}$} & \multirow[t]{3}{*}{ Total } & \multirow[t]{2}{*}{ Mean } \\
\hline $\operatorname{SIPX}(\mathrm{g} / \mathrm{t})$ & \multicolumn{4}{|c|}{ Conditioner -- NaHS $(\mathrm{g} / \mathrm{t})$} & & \\
\hline $\begin{array}{l}\text { Dose } \\
\text { Rates } \\
\end{array}$ & 50 & 100 & 150 & 200 & & \\
\hline 90 & 53.32 & 174.81 & 156.21 & 178.72 & 663.06 & 165.76 \\
\hline 110 & 173.68 & 147.37 & 169.18 & 172.21 & 662.44 & 165.61 \\
\hline 120 & 152.10 & 178.14 & 157.24 & 176.70 & 664.18 & 166.04 \\
\hline 130 & 154.68 & 153.47 & 143.06 & 174.92 & 626.13 & 156.53 \\
\hline TOTAL & 633.78 & 653.79 & 625.69 & 702.55 & 2615.81 & \\
\hline
\end{tabular}
each cell as follows:

We now proceed with the calculations as follows:

(a) The sum of squares due to the collection

$$
s s_{a x}=\frac{1}{8}\left\{\sum R_{l=1}^{k}\right\}-C . F
$$

where $\mathrm{k}$ is the number of treatments (levels of dosages)

C.F: Correction factor $=\frac{1}{32} \sum_{l=1}^{n i} R^{2}$

Thus

$S S_{a x}=\frac{1}{8}\left(663.06^{2}+662.44^{2}+664.18^{2}+626.13^{2}\right)-\frac{1}{32}\left(2615.81^{2}\right)=129.21$

Mean square due to collection treatment, i.e due to the effect of the collector: 


$$
M S_{z a}=\frac{S S_{x a}}{d f}=\frac{S S_{x a}}{k-1}=\frac{129.21}{3}=43.07
$$

Similarly, the sum of squares due to the conditioning treatment:

$S S_{N a}=\frac{1}{8}\left(633.78^{2}+653.79^{2}+625.69^{2}+702.55^{2}\right)-\frac{1}{32}\left(2615.81^{2}\right)=445.93$

Mean square due to conditioning treatment

$M S_{N a}=\frac{S S_{N a}}{d f}=\frac{445.93}{3}=148.64$

(a) Total sum of the squares due to the treatments:

$S S_{T}=R_{i j}^{2}-C . F=\frac{1}{2}\left(153.32^{2}+174.81^{2}+156.21^{2}+178.72^{2}+\ldots+174.92^{2}\right)$ $-\frac{1}{32}\left(2615.81^{2}\right)=1136.30$

(b) The sum of squares due to the interaction of the collector and the conditioner:

$S S_{x a-N a}=S S_{T}-S S_{x a}-S S_{N a}=1136.30-129.21-445.93=561.16$

(c) Mean square due to the interaction of the two reagents

$$
M S_{x a-N a}=\frac{561.16}{9}=62.35
$$

(d) Error sum of squares, $\mathrm{SS}_{\mathrm{E}}$

$$
\begin{aligned}
& S S_{E}=89.47^{2}+63.85^{2}+88.91^{2}+85.90^{2}+. . \\
& .-\frac{1}{2}\left(153.32^{2}+174.81^{2}+156.21^{2}+. .\right)=2192.18
\end{aligned}
$$

Variance of the error for the whole population of recoveries

$$
M S_{\text {ERROR }}=\frac{2192.18}{16}=137.01
$$

From the above data the general form of the equation for calculation of the statistic $\mathrm{F}$ is

$$
F=\frac{M S_{\text {TYPE }}}{M S_{\text {ERROR }}}
$$

Where $\mathrm{MS}_{\mathrm{TYPE}}$ is the mean square of the type of treatment, e.g collection, conditioning etc. A conclusion is reached by comparing the F- Calculated with that obtained from standard statistical tables at $95 \%$ confidence level, and
If $\mathrm{F}_{\mathrm{CAL}}>\mathrm{F}_{\mathrm{TABLES}}$, we reject the hypothesis

If $\mathrm{F}_{\mathrm{CAL}}<\mathrm{F}_{\text {TABLES }}$, we accept the hypothesis

The analysis of variance data for the recovery of total copper is presented table 4 below:

Table 4 : Summary of ANOVA results

\begin{tabular}{|l|c|c|c|c|c|}
\hline \multicolumn{1}{|c|}{ SOURCE OF } & SUM OF & DEGREES OF & MEAN & F & F \\
\cline { 4 - 6 } VARIANCE & SQUARES & REEDOM & SQUARE & CALCULA. & TABLES \\
\hline BETWEEN THE & & & & & \\
\hline $\begin{array}{l}\text { OF THE } \\
\text { COLLECTOR }\end{array}$ & 129.21 & 3 & 43.07 & 0.31 & $\mathrm{~F}_{3,16}=3.24$ \\
\hline $\begin{array}{l}\text { LEVELS OF } \\
\text { THE }\end{array}$ & & & & & \\
\hline CONDITIONER & 445.93 & 3 & 148.64 & 1.1 & $\mathrm{~F}_{3,16}=3.24$ \\
\hline $\begin{array}{l}\text { INTERACTION } \\
\text { OF THE TWO }\end{array}$ & 561.16 & 9 & 62.35 & 0.46 & $\mathrm{~F}_{9,16}=2.54$ \\
\hline $\begin{array}{l}\text { ERROR } \\
\text { BETWEEN }\end{array}$ & & & & & \\
\hline $\begin{array}{l}\text { INDIVIDUAL } \\
\text { RECOVER }\end{array}$ & 2192.18 & 16 & 137.01 & --- & -- \\
\hline
\end{tabular}

From the above table it is clear that we accept the hypothesis since the F-calculated for all treatment types is less than F - tables at $95 \%$ confidence level. We therefore conclude that the changes in the output variables (recoveries) are due to the effect of the different levels collector and conditioner dosages and at the same time due to the mutual interaction of the two treatments.

This shows that any does rate from $90 \mathrm{~g} / \mathrm{t}$ to $130 \mathrm{~g} / \mathrm{t}$ could be the optimum level provided it gives economical levels of recovery and best grade as compared to the plant targets of above $78 \% \mathrm{TCu}$ recovery and $26.72 \% \mathrm{TCu}$ grade.

Since it is very cumbersome and unnecessary to investigate all the sixteen treatment combinations, which are actually in duplicate, it is advisable to proceed with a few probable results which give good grades recoveries, and proceed with a detailed investigation of these only to find the optimum level. The probable results chosen are the ones that gave the highest recoveries and it is among these that the optimum must lie i.e. the optimum reagent dose rate must lie in the region where both the recovery and the grade of the concentrate are highest.

The results of the four most probable combinations of reagents are shown in figure 3 which reviews that $120 \mathrm{~g} / \mathrm{t}$ SIPX with $100 \mathrm{~g} / \mathrm{t}$ NaHS gives the optimum results. 


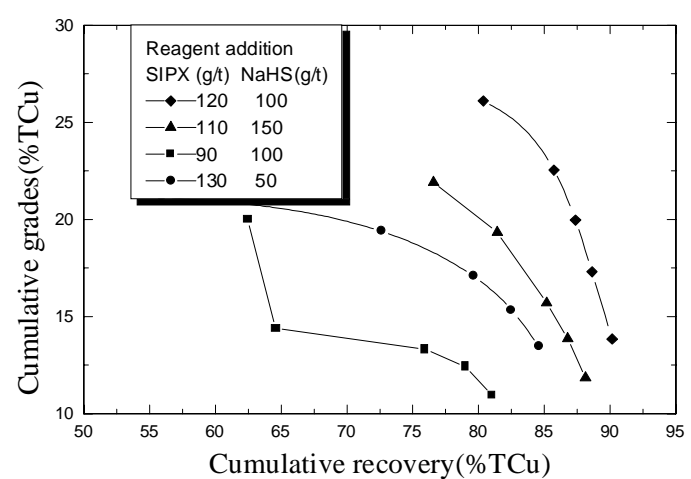

Figure 3: Shows the relationship between the grades and recoveries at different reagent dosage.

This is so because it gives the highest recoveries $(90.16 \% \mathrm{Tcu})$ and the best grade $(26.10 \mathrm{TCu}$. The other graphs have recoveries above targets of the plant, but these cannot be the optimum levels of reagent additions because of the lower grades obtained from them. The low grades could have been due to entrapment of gangue particles during flotation. These could also have been due to:

(a) When batch laboratory flotation tests are carried out, numerous operations are undertaken and consequently experimental errors are inevitable. Thus a number of duplicate flotation tests always produce results which show some significant variance, as was the case in this test work. Some of the operations, which could have led to the discrepancies, are:

(i) Variation in trying to skim or scoop the froth volume at a constant rate of eight pulls per minute. Hence, different concentration weights and grades of the repeat tests were obtained.

(ii) Continuos variations in the pulp density from the beginning to the end of flotation as solids were continuously being removed with the froth and water added to maintain the cell pulp level. This resulted in a change in concentration of all the reagents and $\mathrm{pH}$ levels in the pulp.

\section{CONCLUSIONS.}

By release analysis, it was established that the optimum mesh of grind for the ore was $65 \%$ solids passing $75 \mu \mathrm{m}$ (i.e. 9 minutes grinding time). 9 minutes grinding time gave both the highest weight $\%$ floated and highest recoveries indicating that the degree of liberation or the state of release of the ore is highest at this time.
Furthermore, it was established that the best reagent combination which gave recoveries higher than $78 \% \mathrm{TCu}$ was $120 \mathrm{~g} / \mathrm{t}$ SIPX, Collector and $100 \mathrm{~g} / \mathrm{t}$ Conditioner, NaHS. The optimum plant dosages were $130 \mathrm{~g} / \mathrm{t}$ collector and $200 \mathrm{~g} /$ $\mathrm{t}$ conditioner at the time of conducting the testwork. The new levels of combinations established introduces an approximate $10 \%$ reduction in the collector dosages a $50 \%$ reduction in the conditioner, and this indicates a significant reduction on the costs of the reagents.

The grade obtained at this level $(26.10 \% \mathrm{Tcu})$ also indicates an improvement and with the addition or inclusion of a cleaning stage in the plant, the grades obtainable will be very close to the acceptable market standards.

\section{REFERENCES.}

1. Hines P. R. and J. D. Vincent, “ The early days of froth flotation”. Longman, 1962.

2. Matis K. A. and I. Zouboulis, "An over view of the process". In Flotation: Science and Engineering. Editor K. A. Matis, Marcel Dekker, 1995, New York.

3. Merril C. W. and J. W. Pennington, " The magnitude and significance of flotation in mineral industry in the U.S.A". In Froth flotation $50^{\text {th }}$ anniversary Volume, published by the American Institute of Mining and Metallurgy, 1962.

4. Witika L. K. and B. Dobias, "Electrochemistry of sulphide minerals". In Flotation: Science and Engineering, Edited by K. A. Matis, Marcel Dekker, New York, 1995.

5. Gebhardt J. E. and P. E. Richardson, “ Differential flotation of chalcocite-pyrite bed by electrochemical control”. Min. Metall., Process., 4:140-145, 1987.

6. Simonda E. "Optimisation of baluba east circuit". Final Year Project report, University of Zambia, 1995.

7. Dell C. C, Bunyard M. J. and P. A. Young, "Release Analysis: A comparison technique”. Department of Mining and Mineral Engineering, University of Leeds, United Kingdom, 1985.

8. Gy P. M. "Sampling of particulate materials: theory and practice". Elsevier, Amsterdam, 1982.

9. Vartianen O. and V. Tinnis, “ Factorial design and analysis to obtain optimum operation conditions". 1983 